\title{
The effect of lesions in the septal region on muricide, irritability, and activity in the Long-Evans rat
}

\author{
TAYLOR WALLACE and B. MICHAEL THORNE \\ Mississippi State University, Mississippi State, Mississippi 39762
}

\begin{abstract}
The present research was designed to examine the effects upon mouse killing of different types of damage in and around the septal area. The three types of septal damage incurred were: damage restricted to the septum (SS), damage ventral to the septum (VS), and damage to both the septum and ventrally located structures (LS). Irritability and activity (both horizontal and vertical) were also assessed. The results showed that damage restricted to the septum had no effect on muricide. Extensive damage to the septal region was necessary to increase the probability of mouse killing. All brain-damaged groups were significantly more irritable than the operated controls, with Group VS being the most irritable. Furthermore, killers were found to be significantly more irritable than nonkillers. Group LS animals were the least active of any group on both horizontal and vertical activity assessments. All braindamaged groups were significantly less active than controls in regard to rearing.
\end{abstract}

A variety of manipulations has been found to increase the probability of the mouse-killing response in nonkillers, including food deprivation (Malick, 1975; Rager \& Thorne, 1977), the strain of rat used (Latham \& Thorne, 1974; Thorne, Aaron, \& Latham, 1973), previous experience with mice (Miley \& Baenninger, 1972), type of mouse used (Thorne \& Thompson, 1976), and different types of brain damage. Types of brain damage found to increase the probability of muricide include olfactory bulb lesions (Karli, Vergnes, \& Didiergeorges, 1969; Malick, 1970; Thorne, Aaron, \& Latham, 1973, 1974), ventromedial hypothalamic damage (Karli et al., 1969; Malick, 1970), and septal lesions (Latham \& Thorne, 1974; Miczek \& Grossman, 1972).

While almost all studies examining the effects of either olfactory bulb or ventromedial hypothalamic damage upon muricide have reported increases, the results from studies of septal damage have been more equivocal. For example, Malick (1970) did not obtain an increase in muricide following septal damage in Long-Evans rats, while Miczek and Grossman (1972) obtained killing in $100 \%$ of Sprague-Dawley animals tested after the same recovery period employed by Malick. Even more difficult to explain is the study

This research was performed by the senior author in partial fulfillment of the requirements of the MS degree in Psychology at Mississippi State University. The research was in part supported by an institutional grant awarded to MSU by NSF. Send reprint requests to: B. Michael Thorne, Drawer PF, Mississippi State, Mississippi 39762. by Latham and Thorne (1974), in which rats of the strain tested by Malick showed an increase in killing after septal damage, while no change was seen in animals of the strain used by Miczek and Grossman. Latham and Thorne suggested that the discrepancies might be due to the specific locus of the lesions.

Attempts have been made to determine the neural structures in or near the septal area responsible for other types of aggressive behavior in the rat. Large septal lesions have consistently produced a condition known as the "septal rage syndrome" (e.g., Albert \& Richmond, 1975; Brady \& Nauta, 1955; Olton \& Gage, 1974), characterized by an increase in attack behavior, vocalization, and biting. More restrictive lesions have been made in attempts to localize the rage syndrome. Increases in irritability are sometimes seen after damage to the lateral septal nuclei (Poplawsky \& Johnson, 1973), the anterior portion of the septum (Schnurr, 1972), and the ventral portion of the septum (Thomas \& Van Atta, 1972). By contrast, lesions of the medial septal region produce hypoemotionality (Clody \& Carlton, 1969; Thomas \& Van Atta, 1972) or no change at all in emotionality (Poplawsky \& Johnson, 1973).

Thomas and Van Atta (1972) reported that very large lesions of the septum produce hyperemotionality only if the damage extends to the tissue ventral to the septal nuclei. Lesions not extending ventrally, but dorsally and laterally, do not result in heightened emotionality. Of the ventrally located structures, only damage to the stria terminalis has been found to increase emotionality (Albert \& Richmond, 1975; 
Nolley, 1972; Thomas \& Van Atta, 1972). Paxinos (1976) suggested that the rage is not due exclusively to stria terminalis damage, because ST knife cuts alone cause only mild increases in irritability. Damage to the diagonal band of Broca, a structure ventral to the septum, results in relative docility (Nolley, 1973; Thomas \& Van Atta, 1972).

In addition to the emotionality changes noted previously, lesions of the septal area have been associated with decreased activity. For example, Clody and Carlton (1969) provided evidence that lesions of the medial septum result in decreased wheel-running behavior in albino rats. Paxinos (1975) showed that knife cuts posteroventral to the septum attenuated open-field activity while increasing irritability. Furthermore, he found that anterior septal knife cuts did not significantly affect open-field behavior.

A series of studies by Kemble and Nagel (1975) showed that extensive damage to the septal region caused a significant reduction in rearing behavior that persisted for at least 76 days. This reduction in rearing was not the direct result of deprivation states, emotionality, activity level, competing responses such as grooming or freezing, or a qualitative or durational change in the rearing response. Whether or not the testing environment was familiar or novel made no difference. Beatty, Bengelloun, Vilberg, Klepac, and Steiner (1975) also reported a reduction in the frequency of rearing behavior in open-field testing following septal lesions.

The purpose of the present study was to determine whether or not septal damage, by itself, is sufficient to induce mouse killing or whether more extensive damage is necessary for the induction. Animals with damage ventral to the septum were also tested, since several experimenters have shown such damage to be involved in hyperirritability. Finally, both irritability and activity (including rearing) were assessed in all animals.

\section{METHOD}

\section{Animals}

The animals were 55 adult, male Long-Evans rats between 90 and 120 days of age. The average weight per animal was $426.7 \mathrm{~g}$ (range 346-486). A completely randomized one-way analysis of variance revealed no significant differences between the groups in terms of preoperative weight. Because of death, illness, or inaccurate lesion placement, 15 animals were discarded, leaving a total of 40 rats distributed equally across the four treatment groups.

All of the animals came from breeding stock maintained by the Psychology Department at Mississippi State University and were housed in group cages until at least $24 \mathrm{~h}$ prior to surgery. At this time, the animals were placed in individual hanging cages measuring $17.78 \times 25.40 \times 17.78 \mathrm{~cm}$ and remained housed singly until they were sacrificed. Ad-lib food and water conditions were maintained throughout the study. The colony was maintained under a light-dark cycle of $12 \mathrm{~h}$ light and $12 \mathrm{~h}$ dark.

The 40 animals were randomly assigned by lot to the following four treatment groups: (1) operated control (Group OC); (2) extensive damage to the septum and areas ventral to the septum (Group LS); (3) damage restricted to the septum (Group SS); and (4) damage primarily ventral to the septal area (Group VS).

\section{Surgery and Histology}

The animals were anesthetized with an intraperitoneal injection of a chloral hydrate solution, their heads were shaved, and each was given an injection of Duricilin $(0.2 \mathrm{cc})$ intramuscularly. The animals were then placed in the head holder of a Baltimore stereotaxic instrument, and an incision was made along the midline of the scalp. A line was etched on the skull perpendicular to bregma, which served as a reference point for aligning the anteriorposterior coordinates. A burr hole with a diameter of approximately $3 \mathrm{~mm}$ was drilled, with bregma as a midpoint. The lesions were then produced with a Stoelting lesion-producing device. The lesions were made via a stainless steel electrode that was insulated except for $1.0 \mathrm{~mm}$ at the tip.

The lesion parameters for the brain-damaged groups were as follows: (1) Group LS, $0.0 \mathrm{~mm}$ anterior to bregma, $0.5 \mathrm{~mm}$ lateral to the midsagittal sinus, $6.5 \mathrm{~mm}$ ventral to the dorsal surface of the brain, and $2.0 \mathrm{~mA}$ direct current for $20 \mathrm{sec}$; (2) Group SS, $0.0 \mathrm{~mm}$ anterior to bregma, $0.5-0.75 \mathrm{~mm}$ lateral to the midsagittal sinus, $4.5 \mathrm{~mm}$ ventral to the dorsal surface of the brain, and 1.0-1.5 mA direct current for $10 \mathrm{sec}$; (3) Group VS, $0.0 \mathrm{~mm}$ anterior to bregma, $0.5 \mathrm{~mm}$ lateral to the midsagittal sinus, $6.5-7.0 \mathrm{~mm}$ ventral to the dorsal surface of the brain, 1.0-1.5 mA direct current for $10 \mathrm{sec}$. All animals in each group sustained bilateral damage.

The animal's wound was then closed with autoclips. All operated control animals were subjected to the same procedure, with the exception of the lowering of the electrode. Each animal was then returned to its home cage and allowed 5 days to recuperate.

At the termination of the study, the animals were sacrificed with an overdose of Nembutal and their brains were extracted and placed in a $10 \%$ Formalin solution and allowed to fix for at least $48 \mathrm{~h}$. Each brain was then frozen with a Super HistoFreeze and sliced approximately $80 \mu$ thick by an AO Spencer sliding microtome. Every fourth or fifth section was saved and stored in water until it was placed on a glass slide and photographed. Using an Omega B22 enlarger, the unstained sections were projected $(10 \times)$ onto $5 \times 7$ in. photographic paper. The photographs were then developed and compared with the atlas by Skinner (1971) to determine the extent of damage.

\section{Procedure}

On Postoperative Day 5, a 20-min, 24-h mouse-killing test was administered. An albino mouse was placed into the cage of each rat, and whether or not killing occurred was recorded. Latencies were recorded during the 20-min observation period, and any kills that occurred after the 20 -min observation period received a latency of $24 \mathrm{~h}$. At the end of $24 \mathrm{~h}$, either the live mouse or the remains of the dead mouse were removed. All tests began during the light portion of the cycle.

Beginning on Postoperative Day 6 and continuing until Postoperative Day 10, handling tests were administered. A clipboard was used to cover the top of each cage, and each animal in its cage was carried from the cage rack to an adjacent table on which the handling test was conducted. The handling test consisted of rating the animal on a scale used by Thorne et al. (1973). The components of the scale were as follows: (1) reaction to the perioral presentation of a pencil; (2) reaction to a pencil tap on the flank; (3) ease of capture from the home cage; (4) resistance to handling; (5) amount of vocalization during testing. Each component was rated on a 4-point scale (0-3), and the sum of the ratings was the animal's score for the day. An overall score for each rat was determined by summing its daily scores.

Interobserver reliability assessments were periodically performed by having an independent observer rate the handling 
characteristics. The reliability for summed daily scores using the Pearson $r$ procedure was $r=+0.90$ and for each component was as follows: (1) pencil-visual, $\mathrm{r}=+0.92$; (2) pencil tap, $\mathrm{r}=+0.81$; (3) resistance to capture, $r=+0.76$; (4) resistance to handling, $r=+0.85$; and (5) amount of vocalization, $r=+0.85$. All correlation coefficients were significantly different from zero $(p<.01)$.

Immediately following the handling test, activity was assessed in an open-field apparatus measuring $76.2 \times 76.2 \times 25.4 \mathrm{~cm}$. The box was painted flat black, and the floor was divided by white lines into 25 equal squares. Hardware cloth covered the top. The number of squares crossed and the number of rearings (standing on the hind legs) were recorded during a 1-min period. The apparatus was cleaned after each animal's testing, and the order of testing was varied from day to day so that the behavior of one animal did not consistently affect that of another. Interobserver reliability was quite high: squares traversed, $r=+0.98$, $\mathrm{p}<.01$; rearing, $\mathrm{r}=+0.97, \mathrm{p}<.01$.

\section{RESULTS}

\section{Histology}

LS lesions were very extensive, grossly characterized as the sum of the damage to the other two groups. The lateral and medial septal nuclei incurred almost total destruction in every animal. Major and/or consistent damage was also noted in the following areas: septohypothalamic tract, hippocampus pars anterior, nucleus accombens, diagonal band of Broca, tract and bed nucleus of the stria terminalis, nucleus preopticus pars suprachiasmatica, and the walls of the lateral and third ventricles. Minimal, unilateral, or inconsistent damage was found in the preoptic area, anterior commissure, corpus callosum, columns of the fornix, hypothalamus, medial forebrain bundle (MFB), olfactory tubercle, fornix superior, and the caudate-putamen complex. According to the de Groot plane, the lesions generally extended from 0.0 to $3.5 \mathrm{~mm}$ anterior to bregma, $1.25 \mathrm{~mm}$ on each side of the midline, and extended from the corpus callosum to the base of the brain. Sections A-D in Figure 1 depict the maximum (diagonal lines) and minimum (shaded) extent of damage sustained by Group LS animals.

Lesions in the SS group were characterized by nearly total ablation of both the lateral and medial septal nuclei and the walls of the lateral ventricle. Consistent damage was found in the hippocampus pars anterior, although less extensive. Other structures that received minimal, inconsistent, or unilateral insult were the corpus callosum, diagonal band of Broca, caudateputamen complex, fornix superior, fornix precommissuralis, and the columns of the fornix. Referring to the de Groot plane, the lesions generally extended from 0.5 to $2.5 \mathrm{~mm}$ anterior to bregma, $0.75 \mathrm{~mm}$ on each side of the midline, and were bounded by the corpus callosum dorsally, the caudate-putamen complex laterally, and the anterior commissure ventrally. Sections E-H in Figure 1 reveal the range of damage sustained by Group SS rats.

Most lesions in the VS group involved extensive damage to the medial septal nuclei, diagonal band of
Broca, preoptic nucleus pars suprachiasmatica, and the walls of the third ventricle. Minimal, unilateral, or inconsistent damage was also sustained in the septohypothalamic tract, hippocampus pars anterior, preoptic area, stria terminalis, lateral septal nucleus, anterior commissure, and the walls of the lateral ventricle. Using de Groot as the plane of reference, the lesions generally extended from approximately 1.0 to $2.5 \mathrm{~mm}$ anterior to bregma, $0.75 \mathrm{~mm}$ on each side of the midline, and ventrally from the medial septal nucleus to the base of the brain. Sections I-L in Figure 1 show the range of damage sustained by animals in Group VS.

\section{Muricide}

Inspection of Figure 2 reveals that LS animals killed at a greater rate than any other group, while there are no clearcut differences between VS, SS, and operated control animals. Using the Fisher exact probability test, six pairwise comparisons were performed, two of which were significant. Thus, more LS animals killed than either OC $(p=.0095)$ or VS $(p=.03)$ animals. A trend toward significance was found in the comparison between Groups LS and SS $(p=.08)$. There were so few killers in groups other than LS that comparisons of latencies between groups were not performed; however, a comparison of latencies between LS killers and all other killers revealed a significant difference $(p=$ .048) using the Fisher exact probability test, with LS animals killing with a shorter latency. Care should be taken in interpreting this finding because SS, VS, and OC killers may not be exhibiting the same type of response.

\section{Handling}

It can be seen from inspection of Figure 3 that each Group differentiated itself from the others. Group VS was distinctly the most irritable, followed by Groups LS, SS, and OC, in that order. A KruskalWallis one-way analysis of variance (corrected for tied scores) was performed on the handling data, and significance was found between the treatment groups in regard to the total 5-day scores $[\mathrm{H}(3)=24.40$, $\mathrm{p}<.001$ ]. Six pairwise comparisons were performed using the Mann-Whitney $U$ test; four of them were significant. All brain-damaged groups were significantly more irritable than operated controls (OC vs. VS, $U=0, p<.001$; OC vs. LS, $U=0, p<.001$; OC vs. SS, $U=2, p<.001)$. Group VS was found to be significantly more irritable than Group SS $(U=28, p<.05)$. No other comparison was significant. The mean total 5-day irritability rating for each group was as follows: OC, 1.8 ; SS, 26.5; LS, 33.0; VS, 42.0.

The Friedman two-way analysis of variance disclosed significance in regard to daily scores for groups $\operatorname{VS}\left[\chi_{\mathrm{r}}^{2}(4)=11.24, \mathrm{p}<.05\right]$ and $\operatorname{LS}\left[\chi_{\mathrm{r}}^{2}(4)=13.96\right.$, 

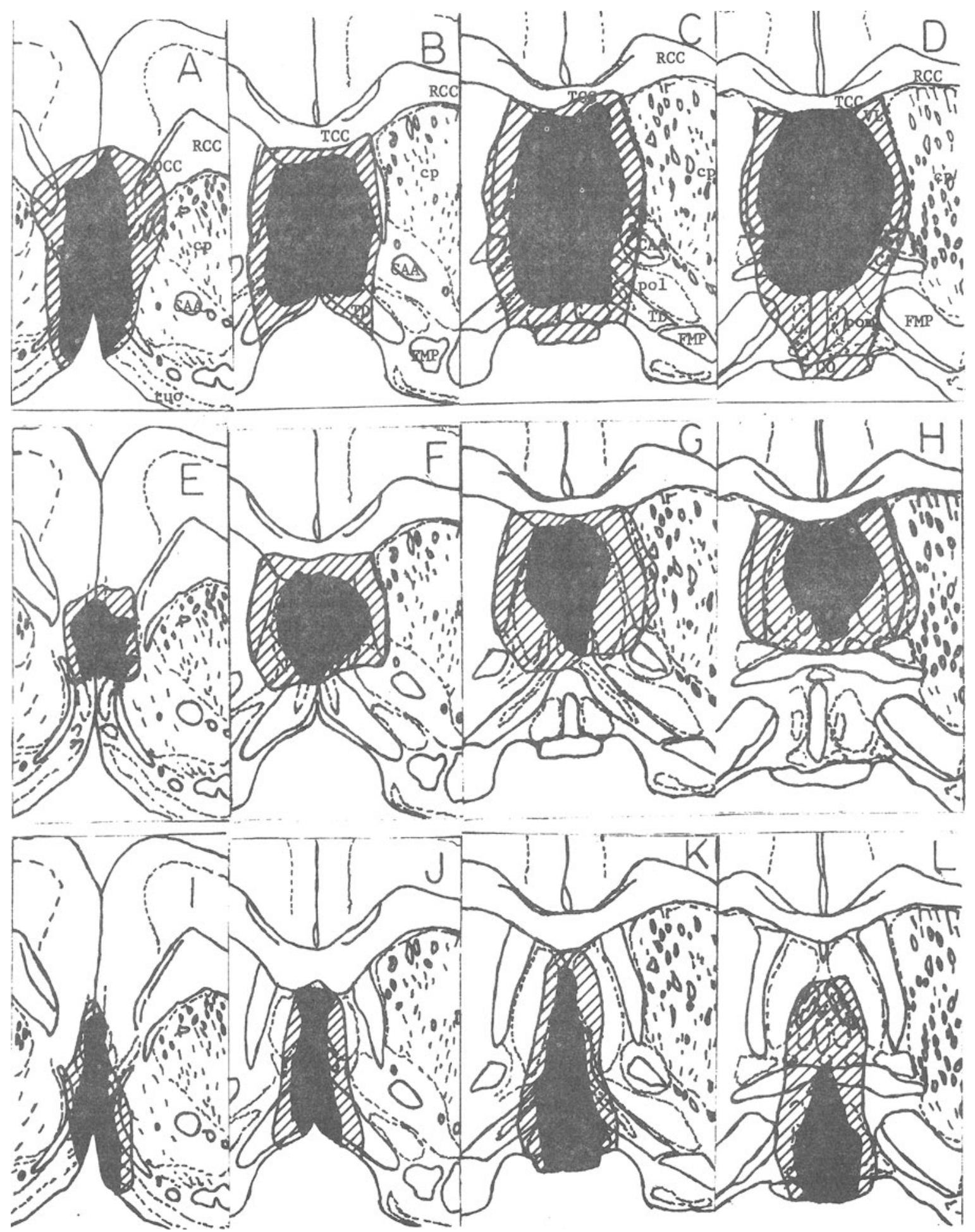

Figure 1. Representative frontal sections (redrawn from the atlas shown in Skinner, 1971) showing the range of damage found in each brain-damaged group. The shaded area represents the smallest lesion, while the largest lesion is indicated by diagonal lines. Sections A-D, Group LS; Sections E-H, Group SS; Sections I-L, Group VS. 


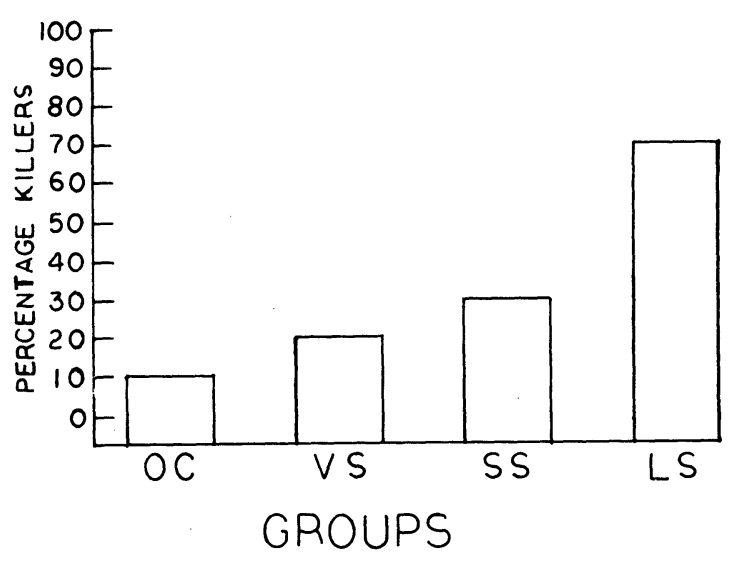

Figure 2. Percentage of killer rats per group ( $N=10$ per group).

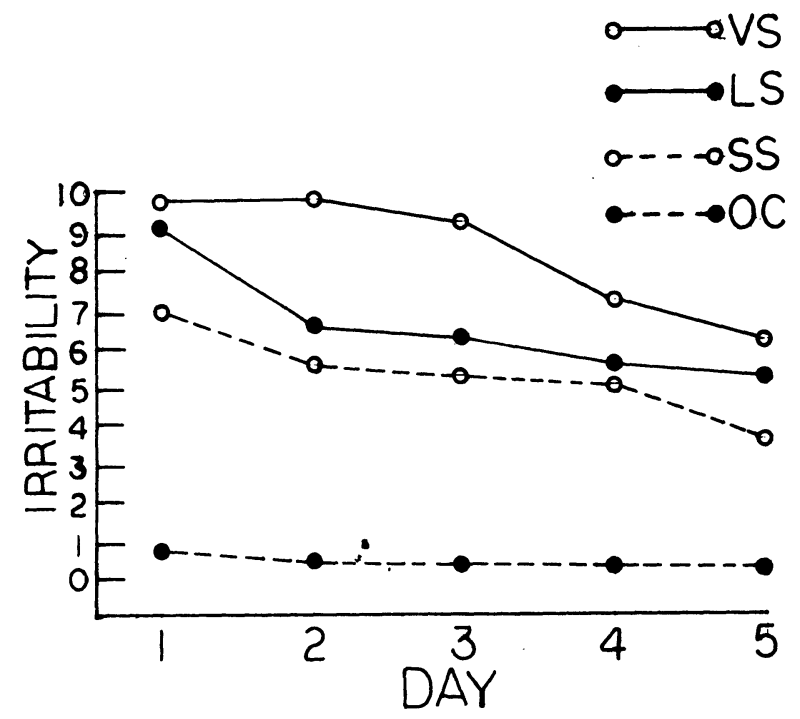

Figure 3. Mean handling score per group over the 5-day testing $\operatorname{period}(\mathbf{N}=10$ per group).

$\mathrm{p}<.01]$. For Group VS, a Wilcoxon matched-pairs signed ranks test revealed that 6 of 10 pairwise comparisons were significant. Scores on Days 4 and 5 were significantly lower than scores on Days 1 ( 1 vs. $4, \mathrm{~T}=4.5, \mathrm{p}<.025 ; 1$ vs. $5, \mathrm{~T}=3.5, \mathrm{p}<$ .025 ), 2 ( 2 vs. $4, \mathrm{~T}=0, \mathrm{p}<.005 ; 2$ vs. $5, \mathrm{~T}=0$, $\mathrm{p}<.005)$, and 3 ( 3 vs. $4, \mathrm{~T}=0, \mathrm{p}<.005 ; 3$ vs. 5 , $\mathrm{T}=1.5, \mathrm{p}<.005)$. For Group LS, the Wilcoxon test showed that 4 of 10 pairwise comparisons were significant. These animals were significantly less irritable on Days $5(\mathrm{~T}=0, \mathrm{p}<.005), 4(\mathrm{~T}=3$, $\mathrm{p}<.005), 3(\mathrm{~T}=0, \mathrm{p}<.005)$, and $2(\mathrm{~T}=1.5$, $\mathrm{p}<.005)$ than on Day 1 . These findings provide evidence for habituation of the handling response over the 5-day testing period.

\section{Horizontal Activity: Squares Crossed}

Figure 4 shows the activity per group in regard to the average number of squares traversed per day.
A Kruskal-Wallis one-way ANOVA revealed no significant differences between the groups on this variable $[\mathrm{H}(3)=6.81, \mathrm{p}>.05]$. However, inspection of Figure 4 indicates that Group LS animals crossed fewer squares than any other group consistently throughout testing. Therefore, individual comparisons of total squares crossed were performed as if there had been a significant overall $\mathrm{H}$. This comparison revealed that Group LS animals were significantly less active than either Group VS $(U=19.5$, $\mathrm{p}<.025)$ or Group OC $(\mathrm{U}=24, \mathrm{p}<.05)$ animals. The means for the total number of squares crossed during testing were: Group OC, 41.2; Group VS, 42.5; Group SS, 32.5; and Group LS, 19.3. The Friedman two-way ANOVA revealed no significant differences between daily assessments of horizontal activity for any treatment group. There was a significant negative correlation $(\mathrm{r}=-0.58, \mathrm{p}<.05)$ between the size of the lesion and the number of squares traversed for LS animals. No other correlation was significant.

\section{Vertical Activity: Rearing}

In regard to rearing, Figure 5 shows that Group OC was the most active group over the 5 days and Group LS consistently exhibited the least amount of vertical activity. A Kruskal-Wallis one-way ANOVA revealed a significant difference among the treatment groups $[\mathrm{H}(3)=16.26, \mathrm{p}<.001]$. The Mann-Whitney $\mathrm{U}$ test showed that five of six pairwise comparisons were significant. All brain-damaged groups were significantly less active than operated controls (OC vs. VS, $U=10, p<.001 ; O C$ vs. $S S, U=23.5, p<$ .05 ; OC vs. LS, $U=0, p<.001$ ). Further, Group LS animals were significantly less active than either Group SS $(U=20.5, p<.05)$ or Group VS $(U=$
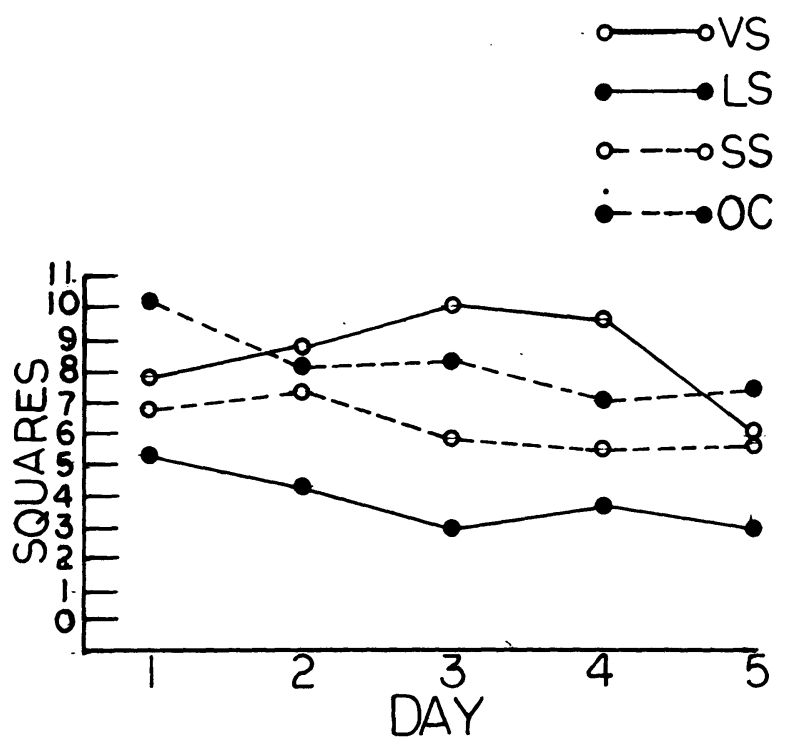

Figure 4. Mean squares crossed per group over the 5-day testing period $(N=10$ per group). 


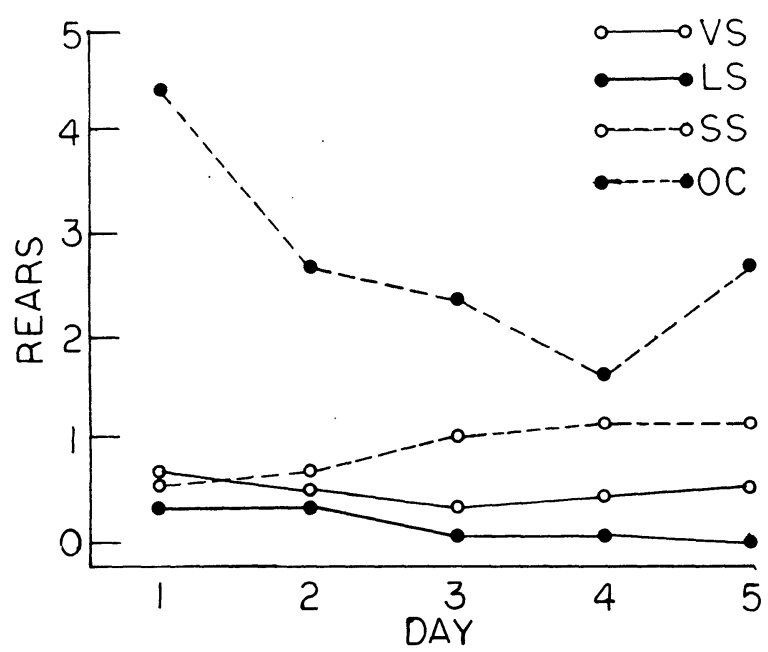

Figure 5. Mean rears per group over the 5-day testing period $(\mathrm{N}=10$ per group $)$.

22.5, $\mathrm{p}<.05)$. The mean for each group was: Group LS, 0.8; Group VS, 2.4; Group SS, 4.5; and Group OC, 13.7.

The Friedman two-way ANOVA showed no significant differences between daily assessments of rearing behavior for any treatment group. There was no significant correlation between the size of the lesions and the number of rears for any brain-damaged group.

\section{DISCUSSION}

The results of the present study indicated that the locus of damage in the septal region is important in whether or not an increase in muricide occurs. Thus, we found that septal damage alone does not significantly increase the probability of mouse killing in Long-Evans rats, nor does damage restricted primarily to structures ventral to the septum. Septal damage in combination with ventral damage was found to cause an increase in the rate of killing, however, and this suggests that the equivocal findings of the role of the septum in muricide may be due in part to differing loci of the damage.

The present results corroborate the findings of Latham and Thorne (1974) and Miczek and Grossman (1972) in finding an increase in muricide following extensive damage to the septal area. The disparate results found by Malick (1970) may be due to the abbreviated length of his muricidal tests. Malick employed a 5-min test, while this study and the study by Latham and Thorne used a 20-min, 24-h test. Only 3 of the 12 brain-damaged killers in this investigation killed within $5 \mathrm{~min}$. All but 1 of the other 9 killed after the 20-min observation period. In addition, a recent report by Rager and Thorne (1977) emphasizes the importance of test length.
It has been reported that septal damage alone does not cause an increase in irritability (Thomas \& Van Atta, 1972; Turner, 1970), but if the damage extends to tissue ventral to the septum, hyperemotionality results (Thomas \& Van Atta, 1972). The results of the present study are in agreement with the study by Thomas and Van Atta in that ventral damage facilitated the appearance of heightened emotionality. However, in agreement with Albert and Richmond (1975), Schnurr (1972), and many others, we also found that damage restricted to the septum is sufficient to bring about irritability.

Although Group LS animals were significantly more irritable than operated controls, they were not the most irritable animals. It is difficult to explain why Group VS was the most irritable group, since the major damage in this group was to the medial septal nuclei and the diagonal band of Broca, both of which have been associated with hypoemotionality (Clody \& Carlton, 1969; Nolley, 1973; Poplawsky \& Johnson, 1973; Thomas \& Van Atta, 1972). It is possible that damage to the preoptic area or some other ventral structure was the cause of the increased irritability exhibited by Group VS animals. The histological material did not permit a more refined analysis of this finding.

Consistent with other findings in the literature (e.g., Brady \& Nauta, 1955; Malick, 1970), the hyperirritability of the septal animals in this study habituated over the 5-day testing period. After the initial 5-day testing period, a few animals from each group received two additional handling tests at intervals of 1 week. By the end of the second assessment, the most irritable animal in any group received an irritability rating of 3 out of a maximum possible score of 15 .

The finding that the animals that killed were significantly more irritable than those animals that did not kill is in direct opposition to previous results from this laboratory (Latham \& Thorne, 1974; Thorne et al., 1973, 1974). However, at least one other experimenter (Cain, 1974) has found a significant correlation between killing and irritability in brain-damaged animals.

The results of this experiment show that damage restricted to the septum does not cause a reduction in horizontal activity (squares crossed). Damage to the medial septal nuclei was found to decrease wheel running (Clody \& Carlton, 1969). However, in the present study, Group VS animals received extensive damage to the medial septum and showed no reduction in activity, but rather were the most active animals on 3 of the 5 days of testing (see Figure 4). This discrepancy may be due to either differences in the locus of damage or to the different task requirements, i.e., wheel running vs. open field.

The assessment of vertical activity (rearing) corroborates the findings of Beatty et al. (1975) and Kemble 
and Nagel (1975) in that lesions of the septal area attenuated rearing. Further, the results of the present study show that this finding may not necessarily be due to an extensive lesion in the septal area. Although Kemble and Nagel made lesions comparable to Group LS lesions and reported the effect, all of the brain-damaged groups in this investigation displayed significantly less rearing behavior than controls.

In summary, the present data indicate that damage restricted to the septal region is unlikely to cause an increase in muricide unless damage is incurred to ventral structures as well. All brain-damaged groups were significantly more irritable than the operated controls and damage ventral to the septum caused a profound increase in irritability, suggesting that damage to structures in this area facilitates a rage response. Damage to the septum alone resulted in a significant increase in irritability. Killers were found to be significantly more irritable than nonkillers. Group LS animals were found to be the least active of any group for both horizontal and vertical activity, while all brain-damaged groups were significantly less active than controls in regard to rearing.

\section{REFERENCES}

Albert, D. J., \& Richmond, S. E. Septal hyperreactivity: A comparison of lesions within and adjacent to the septum. Physiology and Behavior, 1975, 15, 339-347.

Beatty, W. W., Bengelloun, W. A., Vilberg, T. R., KLEPAC, R. K., \& Steiner, J. M. Differential effects of US intensity and flooding on the acquisition and extinction of one-way avoidance responding in female rats with septal lesions. Behavioral Biology, 1975, 13, 311-321.

BRADY, J. B., \& NaUta, W. J. H. Subcortical mechanisms in emotional behavior: The duration of affective changes following septal and habenular lesions in the albino rat. Journal of Comparative and Physiological Psychology, 1955, 48, 412-420.

CAIN, D. P. Olfactory bulbectomy: Neural structures involved in irritability and aggression in the male rat. Journal of Comparative and Physiological Psychology, 1974, 86, 213-220.

Clody, D. E., \& CARLton, P. L. Behavioral effects of lesions of the medial septum of rats. Journal of Comparative and Physiological Psychology, 1969, 67, 344-351.

Kari, P., Vergnes, M., \& Didiergeorges, F. Rat-mouse interspecific aggressive behavior and its manipulation by brain ablation and by brain stimulation. In S. Garattini \& E. B. Sigg (Eds.), Aggressive behavior. New York: Wiley, 1969.

Kemble, E. D., \& Nagel, J. A. Persistent depression of rearing behavior in rats after extensive septal lesions. Journal of Comparative and Physiological Psychology, 1975, 89, 747-758.

Latham, E. E., \& Thorne, B. M. Septal damage and muricide: Effects of strain and handling. Physiology and Behavior, $1974,12,521-526$.
Malick, J. B. A behavioral comparison of three lesion-induced models of aggression in the rat. Physiology and Behavior, 1970, 5, 679-681.

Malick, J. B. Effects of age and food deprivation on the development of muricidal behavior in rats. Physiology and Behavior, 1975, 14, 171-175.

Miczek, K. A., \& Grossman, S. P. Effects of septal lesions on inter- and intraspecies aggression in rats. Journal of Comparative and Physiological Psychology, 1972, 79, 37-45.

Miley, W. M., \& BaenNinger, R. Inhibition and facilitation of interspecies aggression in septally lesioned rats. Physiology and Behavior, 1972, 9, 379-384.

Nolley, D. A. Agonistic behavior after stria terminalis lesions in the rat. Psychonomic Science, 1972, 28, 182-184.

Nolley, D. A. Depression of agonistic behavior after diagonal band of Broca lesion in rats. Journal of Comparative and Physiological Psychology, 1973, 84, 365-369.

Olton, D. S., \& GAGE, F. H. The role of the fornix in the septal syndrome. Physiology and Behavior, 1974, 13, 269-279.

Paxinos, G. The septum: Neural systems involved in eating, drinking, irritability, muricide, copulation, and activity in rats. Journal of Comparative and Physiological Psychology, 1975, 89. 1154-1168.

Paxinos, G. Interruption of septal connections: Effects on drinking, irritability and copulation. Physiology and Behavior, 1976, 17, 81-88.

Poplawsky, A., \& Johnson, D. A. Open-field behavior of rats following lateral or medial septal lesions. Physiology and Behavior, 1973, 11, 845-854.

RAgER, K., \& ThORne, B. M. The effects of food deprivation and length of test on muricide in rats. Physiology and Behavior, 1977, 18, 759-762.

SCHNURR, R. Localization of the septal rage syndrome in Long-Evans rats. Journal of Comparative and Physiological Psychology, 1972, 81, 291-296.

SKInNer, J. E. Neuroscience: A laboratory manual. Philadelphia: Saunders, 1971.

Thomas, J. B., \& VAN Atta, L. Hyperirritability, lever-press avoidance, and septal lesions in the albino rat. Physiology and Behavior, 1972, 8, 225-232.

Thorne, B. M., Aaron, M., \& Latham, E. E. Effects of olfactory bulb ablation upon emotionality and muricidal behavior in four rat strains. Journal of Comparative and Physiological Psychology, 1973, 84, 339-344.

Thorne, B. M., Aaron, M., \& Latham, E. E. Olfactory system damage in rats and emotional, muricidal, and rat pup killing behavior. Physiological Psychology, 1974, 2, 157-163.

Thorne, B. M., \& Thompson, M. E. The effect of different types of mice upon muricidal behavior in the Long-Evans rat. Physiological Psychology, 1976, 4, 238-246.

TURNER, B. H. Neural structures involved in the rage syndrome of the rat. Journal of Comparative and Physiological Psychology, 1970, 71, 103-113.

(Received for publication July 18, 1977; revision accepted November $17,1977$. 